\title{
Física ambiental: uma análise dos conhecimentos dos alunos da EJA
}

\author{
Erondina Azevedo Lima ${ }^{1}$ \\ Iramaia Jorge Cabral de Paulo² \\ Carlo Ralph De Mussis ${ }^{3}$ \\ Elis Dener Lima Alves ${ }^{4}$
}

\section{Resumo}

O presente trabalho teve como objetivo analisar a existência ou não de relação entre os conceitos físicos trabalhados em sala de aula na Educação de Jovens e Adultos (EJA) com o conteúdo das campanhas de educação ambiental realizadas pelo Estado de Mato Grosso. Partiu-se da ideia de que é necessário estabelecer uma estreita articulação entre os conteúdos trabalhados em sala e o cotidiano dos alunos da Educação de Jovens e Adultos. Os dados apresentados foram obtidos a partir da aplicação de um questionário estruturado que procurou verificar o processo de compreensão dos alunos da EJA a respeito das campanhas de mídia impressa (folders). Os resultados apontam dificuldades dos alunos em relacionar os conhecimentos da disciplina de Física com o conteúdo das campanhas. A compreensão disso se torna relevante, pois possibilita que ações efetivas sejam feitas para melhoria do ensino de Física, o que contribuirá para maior entendimento e efetividade das campanhas ambientais.

Palavras-chave: Meio ambiente. Física. Educação ambiental.

\section{Introdução}

A relação entre o homem e a natureza é bem conturbada; traços culturais apontam para um comportamento de supremacia do homem em relação à

1 Doutoranda do Programa de Pós Graduação em Física Ambiental da Universidade Federal de Mato Grosso. erondinaazevedo@ yahoo.com.br

2 Professora Doutora do Programa de Pós-Graduação em Física Ambiental da Universidade Federal de Mato Grosso. iramaiaj@gmail.com

3 Professor Doutor do Programa de Pós-Graduação em Física Ambiental da Universidade Federal de Mato Grosso. demusis@uol.com.br

4 Mestre em Física Ambiental. elisdener@hotmail.com 
natureza. Há muitos séculos essa relação exerce impactos, que se acentuam com o contínuo desenvolvimento econômico associado ao crescimento populacional, verificando-se, ao longo dos séculos, excessiva exploração dos recursos naturais.

A crise ambiental é uma das faces da sociedade contemporânea e de seu modelo de desenvolvimento econômico. O conhecimento parcial sobre o meio ambiente é uma das principais causas de destruição dos ecossistemas. Dajoz (2005) afirma que os ecossistemas seguem as leis da termodinâmica e, particularmente, da termodinâmica de sistemas abertos, portanto, podem evoluir para um estado de organização cada vez mais complexo. Segundo Reichardt e Timm (2004) o sistema solo-planta-atmosfera, como parte da biosfera, as plantas, os animais e os microorganismos que vivem em determinadas áreas e constituem uma comunidade biológica estão interligados por complexa rede de relações funcionais que inclui o ambiente no qual existem. No entanto, o homem violou todas as leis do equilíbrio e tem ameaçado tanto a natureza como sua própria existência no planeta. Talvez o maior desafio da humanidade hoje seja aliar conhecimento e desenvolvimento com conservação dos recursos naturais.

A educação fornece ao indivíduo meios para entender o mundo e seu papel na sociedade. Em uma educação científica, é necessário que se redefina o processo de ensino-aprendizagem em que haja a participação do indivíduo no processo de proposição de soluções para estimular o aprendiz a aprender.

Bachelard (1996, p. 29) afirma que na formação do espírito científico o primeiro obstáculo é a experiência primeira, a experiência colocada antes e acima da crítica, crítica esta que é necessariamente elemento integrante do espírito científico. O homem movido pelo espírito científico deseja saber para, imediatamente, melhor questionar. De acordo com os Parâmetros Curriculares Nacionais (PCNs, 2010) o que a Física deve buscar no Ensino Médio é assegurar que a competência investigativa resgate o espírito questionador (científico), o desejo de conhecer o mundo em que se habita. Mesmo que este aluno só tenha contato com ela no Ensino Médio, este contato é importante, pois pode possibilitar ampliação no leque do conhecimento. Evidentemente que os conteúdos ministrados em sala de aula não são suficientes para um aluno entender de quântica, nanotecnologia, física 
ambiental etc., mas a Física pode despertar curiosidade ou até mesmo estimulá-lo a conhecer mais sobre a natureza, o meio em que vive, talvez até uma inclusão no mundo da ciência. A alfabetização científica pode ser considerada como dimensão para potencializar alternativas que privilegiam uma educação mais comprometida (CHASSOT, 2003).

De acordo com o programa da Organização das Nações Unidas para a Educação, a Ciência e a Cultura (UNESCO) em 2003, intitulado Ciência na Escola um Direito para Todos, é urgente que as mudanças preconizadas cheguem até a sala de aula e que as ações para a qualidade da educação produzam impactos diretos na aprendizagem dos alunos. Continuar aceitando que grande parte da população não recebe formação científica e tecnológica de qualidade agravará as desigualdades do país e significará seu atraso econômico e político no mundo globalizado. Investir para constituir uma população cientificamente preparada é cultivar para colher cidadania e produtividade, que melhoram as condições de vida de todo o povo. O ensino de Física é um dos caminhos importantes para a educação científica e pode, mais especificamente, tratar de conceitos e fenômenos fundamentais para a compreensão das relações biosfera-atmosfera-geosfera. Na busca pela inclusão social, a educação de jovens e adultos (EJA) é considerada um direito, pois inclui a qualificação e a requalificação profissional. É uma modalidade necessária da educação básica reservada ao atendimento de alunos que não tiveram acesso, condições ou não conseguiram concluir o Ensino Fundamental e Médio na idade própria. Na Lei de Diretrizes e Bases da Educação Nacional n 9.394/96, consta no Título V, Capítulo II, Seção V, dois artigos que se referem especificamente, à Educação de Jovens e Adultos:

Art. 37. A educação de jovens e adultos será destinada àqueles que não tiveram acesso ou continuidade de estudos no ensino fundamental e médio na idade própria.

Art. 38. Os sistemas de ensino manterão cursos e exames supletivos, que compreenderão a base nacional comum do currículo, habilitando ao prosseguimento de estudos em caráter regular. (BRASIL, 1996).

O Plano Nacional de Educação (PNE, 2010) estabelece como meta e prioridade alfabetizar 10 milhões de jovens e adultos, em cinco anos e até o final de 2011, 
erradicação do analfabetismo entre adultos e jovens, garantindo Ensino Fundamental e Médio a todos que não tiveram acesso ou não conseguiram concluir. A formação do aluno da EJA abrange ciências exatas e ciências humanas, além das vivências de cada indivíduo que, no contexto escolar, acabam contribuindo para a formação de cidadãos conscientes de seus direitos e deveres.

Torna-se necessário que, ao se trabalhar Física em sala de aula, o professor busque trabalhar com a realidade dos alunos, pois assim estará oferecendo ao aluno da EJA um universo acessível e conhecido, possibilitando assim, que ele possa compreender problemas que afetam sua vida na comunidade e no mundo. Este trabalho investigou junto aos alunos da EJA se havia relação dos conceitos físicos trabalhados em sala com o conteúdo das campanhas de educação ambiental realizadas pelo estado de Mato Grosso.

\section{Material e métodos}

A pesquisa foi desenvolvida em três etapas, sendo que a primeira consistiu em visitas aos órgãos governamentais responsáveis pelo encaminhamento e desenvolvimento das campanhas de educação ambiental na última década. Sendo montado um banco de dados com o material que foi coletado, em seguida foram selecionados quatro folders entre outros materiais como cartilhas, livros e panfletos de encontros com variados temas. Foram escolhidos os folders com os seguintes temas: Queimada, Desmatamento, Água e Enchente. A segunda etapa consistiu na elaboração e validação do questionário estruturado com 7 questões, para serem respondidas com base na leitura prévia dos folders de educação ambiental.

$\mathrm{Na}$ terceira etapa, foi realizada uma análise qualitativa e quantitativa dos dados obtidos por meio dos questionários. 
Participaram desta pesquisa quatro escolas públicas de Educação de Jovens e Adultos de Cuiabá e Várzea Grande, escolhidos aleatoriamente por meio de sorteio. Ao todo participaram 140 alunos do $3^{\circ}$ ano do Ensino Médio.

Em aulas cedidas pelas direções das escolas, agendadas com antecedência, nada se explicou sobre o conteúdo dos folders para os alunos. Em sala, a pesquisadora se apresentou e, em seguida, entregou os folders junto com o questionário, sendo explicado que eles precisariam ler e respondê-lo de forma individual. A aplicação foi realizada em duas aulas, nas turmas de terceiro ano do Ensino Médio. De posse dos questionários preenchidos, a análise escolhida foi de agrupamento hierárquico. Segundo Hair Junior et al. (2009) Análise de Agrupamentos ou Agrupamento em Árvore (Tree clustering) tem por finalidade agrupar as variáveis, conforme a sua proximidade ou características comuns, buscando mostrar a homogeneidade e a heterogeneidade entre os grupos. Na análise, utilizamos distância euclidiana simples, medida usada para encontrar a similaridade, e método de Ward. A classificação foi feita no programa Statistica 8.0 e Excel 2007.

\section{Resultados e discussões}

Para a interpretação dos dados, foram gerados dendrogramas para cada pergunta do questionário. Figura 1, uma das questões analisadas. Em seguida foi traçada uma linha de corte no dendrograma para que fossem observados os agrupamentos gerados pelas características similares de acordo com as respostas obtidas dos 140 alunos. O critério utilizado para corte do agrupamento foi relacionado diretamente à escala semântica definida, ou seja, onde se formaram dois ou três grupos. Finalmente, a partir da observação e hierarquização do grupo, fez-se uma relação com os discursos dos alunos. A transcrição das repostas dos alunos pesquisados estão mantidas na íntegra. 
Figura 1 - Você consegue identificar alguns conceitos físicos nestes folders, quais?

Você consegue identificar algum conceito físico nestes folders, quais?

Método de Ward

Distância Euclidiana

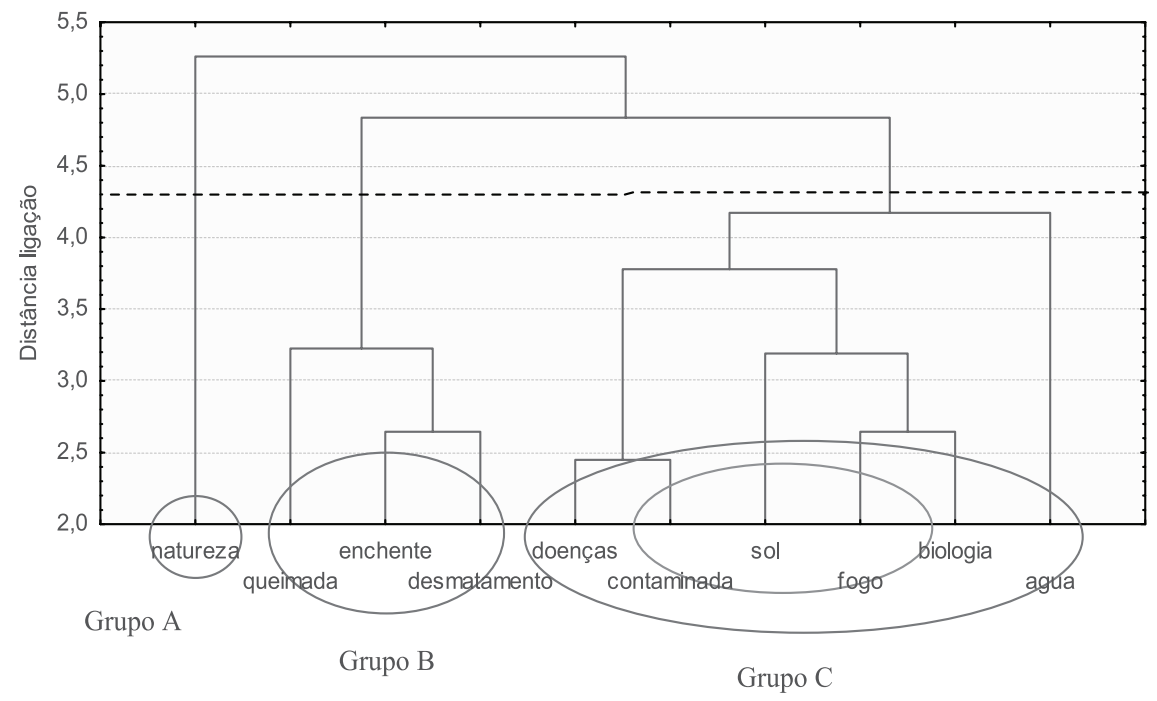

O dendrograma mostra que a maioria dos alunos questionados relacionou a Física à natureza (grupo $\mathrm{A}$ ), uma relação entre o conteúdo, provavelmente tenha origem na definição da Física, que muitos autores trazem no início da disciplina. Maximo e Alvarenga (1997) definem Física como ciência que estuda a natureza. A palavra física tem sua origem no termo grego physiké, que significa natureza. É possível que os alunos tenham relacionado a definição com os conteúdos das campanhas apresentados.

No grupo A, o discurso dos alunos salientou os seguintes aspectos:

“[...] destrói a natureza e os animais." (Aluno 83, Pólo I, Encarregado de produto, 19 anos).

“[...] naturais e humanas” (Aluno 30, Pólo II, Estudante, 18 anos).

A análise aponta que três alunos associaram conceitos físicos com os conteúdos dos folders. 
O aluno 21 relacionou "temperatura e queimada" e no folder água, citou "umidade." (Aluno 21, Pólo II, Encarregado, 37 anos).

O aluno 84 associou calor queimada e umidade à enchente: "[...] Calor [...] umidade”. (Aluno 84, Pólo I Estudante, 17 anos).

Ocorreu no discurso do aluno 4 uma relação da queimada com a ocorrência de baixa umidade e de desmatamento com queimada.

"[...] gera baixa umidade."

“[...] gera queimada" (Aluno 4, Pólo IV, Conferente, 24 anos).

No Grupo B, houve uma identificação dos temas abordados com queimada e maior similaridade entre as palavras enchente e desmatamento:

"Sim, a queimada é provocada pelo homem." (Aluno 85, Pólo I, Mestre de obras, 40 anos).

"[...] desestrutura o solo e a flora e provoca o desequilíbrio da natureza." (Aluno 99, Pólo III, Mecânico, 34 anos).

“[...] queimada e doenças respiratórias" (Aluno 97, Pólo III, Comerciante, 39 anos).

No Grupo C, a relação com doenças, contaminação no subgrupo, relação com a biologia e os elementos água e fogo:

“[...] onde há queimada causada pelo sol." (Aluno 08, Pólo IV, Vendedor, 30 anos).

“[...] o fogo afeta diretamente a físico-química e a biologia." (Aluno 15, Pólo IV, não informada). 


\section{Considerações finais}

Constatou-se nos resultados analisados, uma dificuldade dos alunos da EJA em relacionar os conteúdos físicos com os conteúdos abordados nas campanhas. Dos 140 alunos que participaram da pesquisa, apenas três conseguiram obter essa relação. A maioria dos alunos não conseguiu associar os conteúdos da disciplina de Física com os temas dos folders.

Na perspectiva da educação científica, é importante questionar os valores dos alunos às suas relações com o meio ambiente, fazendo entender que os conteúdos ministrados na disciplina de Física estão ligados às questões ambientais e científicas, ou seja, seria necessária uma melhoria da abordagem dos conteúdos de Física para os alunos da Educação de Jovens e Adultos para contribuir com a compreensão de conhecimentos, procedimentos e valores que permitam aos estudantes tomarem decisões e perceberem a utilidade da ciência e suas aplicações na melhoria da qualidade de vida.

\section{Physical Environment: an analysis of students' knowledge of adult education}

\section{Abstract}

This study aimed to examine whether or not the relationship between physical concepts worked in the classroom in the Education of Youth and Adults (EYA) to the content of environmental education campaigns conducted by the State of Mato Grosso. We started from the idea that there should be a close connection between the content worked in class and the daily life of students of Youth and Adults. The data were obtained from the application of a structured questionnaire which sought to verify the process of students' understanding of EYA about the campaigns of print media (brochures). The results show students' difficulties in relating the knowledge of Physics to the content of campaigns. Understanding this becomes relevant, since it enables effective actions are undertaken to improve the teaching of physics, which will contribute to greater understanding and effectiveness of environmental campaigns. 
Keywords: Environment. Physics. Environmental education.

\section{Referências}

BACHERLAD, G. A formação do espírito cientifico. Rio de Janeiro: Contraponto, 1996.

BRASIL. Lei de Diretrizes e Bases da Educação Nacional. Lei no 9.394, de 20 de dezembro de 1996. Estabelece as diretrizes e bases da educação nacional. Disponível em: <http://portal.mec.gov.br/arquivos/pdf/ldb.pdf >. Acesso em: 22 set. 2010.

BRASIL. PCNs: Parâmetros Curriculares Nacionais. Disponível em: <http://www. mec.gov.br>. Acesso em: 18 maio 2010.

BRASIL. PNE: Plano Nacional de Educação. Disponível em: <http://www.mec.gov. br>. Acesso em: 16 jun. 2010.

CHASSOT, A. I. A alfabetização científica fazendo inclusão social. In: CONGRESSO INTERNACIONAL DE EDUCAÇÃO, 3., 2003, São Leopoldo. Anais... Educação Unisinos, São Leopoldo, v. 7, p. 74, 2003. Número especial.

DAJOZ, R. Princípios de ecologia. 7. ed. Porto Alegre: Artmed, 2005.

HAIR, J. F. J. et al. Análise multivariada de dados. 6. ed. Porto Alegre: Bookman, 2009. MÁXIMO, A; ALVARENGA, B. Física. São Paulo: Scipione, 1997.

REICHARDT, K.; TIMM, L. C. Solo, planta e atmosfera: conceitos, processos e aplicações. São Paulo: Manole, 2004.

UNESCO. Ciência na escola um direito de todos. Disponível em: <http://www.unesco. org >. Acesso em: 20 set. 2010. 


\section{Para publicar na revista Universitas Humanas, acesse 0 endereço eletrônico www.publicacoesacademicas.uniceub.br. Observe as normas de publicação, para facilitar e agilizar o trabalho de edição.}

